ARTICLE

DOI: $10.1038 / s 41467-018-06549-8$

\title{
Sustainable scalable synthesis of sulfide nanocrystals at low cost with an ionic liquid sulfur precursor
}

\author{
Bin Yuan ${ }^{1,2}$, Timothy Karl Egner ${ }^{3}$, Vincenzo Venditti ${ }^{3,4}$ \& Ludovico Cademartiri (i) ${ }^{1,2,5}$
}

Increasing the sustainability of nanocrystals is crucial to their application and the protection of the environment. Sulfur precursors for their synthesis are commonly obtained through multiple steps from $\mathrm{H}_{2} \mathrm{~S}$, only to be converted back to $\mathrm{H}_{2} \mathrm{~S}$ during the synthesis of the nanocrystals. This convoluted process requires energy, reduces yields, increases waste and auxiliaries, and complicates recycling. Using $\mathrm{H}_{2} \mathrm{~S}$ directly could drastically improve sustainability, but is prevented by toxicity and handling. We here show that $\mathrm{H}_{2} \mathrm{~S}$ is stabilized by reaction with oleylamine (the most common and versatile ligand in nanoparticle synthesis) to form an ionic liquid precursor that addresses all major principles of green chemistry: it is made in one exothermic step, it leaves the reaction yielding a safer product and allowing the separate recycling of the precursors, and it produces high quality nanocrystals with high yields (sulfur yield $>70 \%$ ) and concentrations $\left(90 \mathrm{~g} \mathrm{~L}^{-1}\right)$ in ambient conditions.

\footnotetext{
${ }^{1}$ Department of Materials Science \& Engineering, lowa State University of Science and Technology, 2220 Hoover Hall, Ames, IA 50011, USA. ${ }^{2}$ Department of Chemical \& Biological Engineering, lowa State University of Science and Technology, Sweeney Hall, Ames, IA 50011, USA. ${ }^{3}$ Department of Chemistry, lowa State University, Hach Hall, Ames, IA 50011, USA. ${ }^{4}$ Roy J. Carver Department of Biochemistry, Biophysics and Molecular Biology, lowa State University, Ames, IA 50011, USA. ${ }^{5}$ Ames Laboratory, U.S. Department of Energy, Ames, IA 50011, USA. Correspondence and requests for materials should be addressed to L.C. (email: Icademar@iastate.edu)
} 
S ustainability is an important and necessary driver for new chemistry. For example, the translation of colloidal nanoparticles to technologies is limited by the poor sustainability of their synthesis ${ }^{1-3}$. According to the principles of green chemistry $^{4}$, a renewable feedstock that leads to a product with high yield and atom economy, with little to no waste, the smallest number of steps, minimal processing and solvents, high-energy efficiency and safety is always preferable ${ }^{5-7}$. Finding such a precursor for the synthesis of nanoparticles is very challenging 8,9 because their size and shape have to be tightly controlled to yield the desired physical properties. Therefore, less sustainable synthetic approaches ${ }^{5,10,11}$ (e.g., high-temperature reactions ${ }^{12}$, reactions carried out at low concentration $(\mathrm{mM})$, non-stoichiometric reaction mixtures ${ }^{13}$, size-selective precipitation ${ }^{14}$, terminating reactions well before their completion ${ }^{15}$ due to ripening at low supersaturation $^{2}$ ) are usually used to obtain the desired particle quality.

Efforts to find sustainable approaches to nanoparticle synthesis (mostly oxides and metals, rarely other compositions ${ }^{11,16,17}$ ) have focused on finding renewable feedstocks ${ }^{2,16-21}$. Other green chemistry principles, such as reducing waste, recycling, improving yield and atom economy, and minimizing auxiliaries and reaction steps have rarely been addressed ${ }^{13,22,23}$.

Hydrogen sulfide is the most abundant (and in part renewable) sulfur feedstock ${ }^{24,25}$. Traditional precursors for the synthesis of sulfide nanocrystals (e.g., elemental sulfur $\left(\mathrm{S}_{8}\right)$, Bis(trimethylsilyl) sulfide $\left((\mathrm{TMS})_{2} \mathrm{~S}\right)$, thiols, xanthates, dithiocarbamates, thiourea, substituted thioureas) are obtained from $\mathrm{H}_{2} \mathrm{~S}$ through multiple energy/material intensive steps ${ }^{26}$ (Fig. 1a). Usually through the application of heat, these precursors release $\mathrm{H}_{2} \mathrm{~S}$ during the synthesis (and, if unreacted completely, during the purification process), often together with a number of by-products. ${ }^{27-30}$ It has been shown that $\mathrm{H}_{2} \mathrm{~S}$ is the active sulfur source in several syntheses ${ }^{2,31}$. In summary, a lot of energy and chemicals are used to store $\mathrm{H}_{2} \mathrm{~S}$ into a dirtier (but safer) precursor of itself, and to convert it back to $\mathrm{H}_{2} \mathrm{~S}$ to initiate the synthesis.

In this paper, we show how an ionic liquid precursor formed from the reaction between $\mathrm{H}_{2} \mathrm{~S}$ and oleylamine (OLA) addresses all the most relevant green chemistry principles for the synthesis of sulfide nanocrystals, and allows for a sustainable synthesis of nanoparticles, from feedstock to product, in two synthetic steps (Fig. 1a, b). It is worth pointing out that ionic liquids have shown

a

Traditional approach

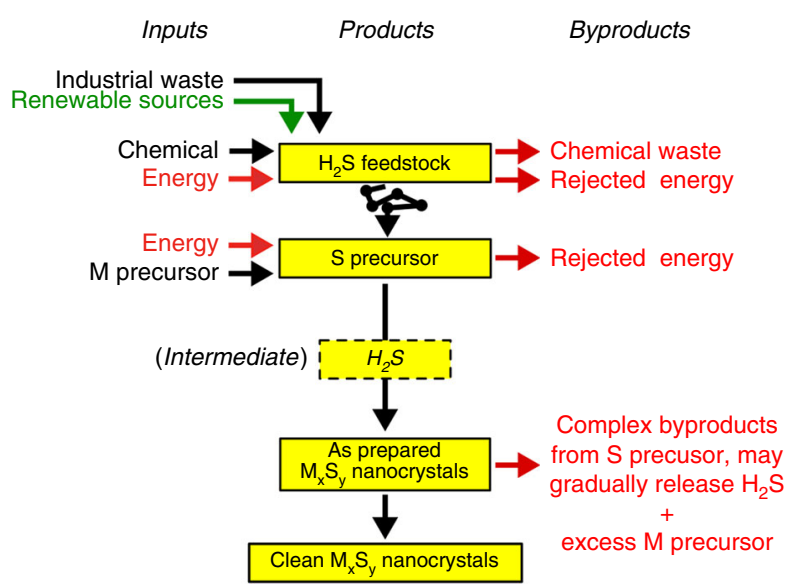

great potential in sustainable applications ${ }^{32-34}$, such as serving as green solvents for synthesis and catalysis ${ }^{35-37}$. Here an ionic liquid is used as a reaction precursor for the synthesis of monodisperse colloidal nanocrystals ${ }^{38-43}$. Besides achieving sustainable synthesis, this ionic liquid sulfur precursor also shows the capability of synthesising metal sulfide nanocrystals under large scale (i.e. liter scale and $>100 \mathrm{~g}$ scale) and at low cost.

\section{Results}

Achieving a sustainable synthetic process using oleylammonium hydrosulfide (OLAHS). $\mathrm{H}_{2} \mathrm{~S}$ is commonly trapped and stabilized in industrial processes by scrubbing it with amines to form ammonium hydrosulfide salts ${ }^{44}$. By scrubbing $\mathrm{H}_{2} \mathrm{~S}$ with OLA - one of the most commonly used ligands in nanoparticle synthesis $^{45}$, and a biorenewable chemical-we discovered that the resulting salt, OLAHS, is a stable, highly viscous ionic liquid that forms exothermically and quantitatively. Using OLAHS as a precursor releases $\mathrm{H}_{2} \mathrm{~S}$ and OLA in situ. The former reacts or leaves the system as a gas to be scrubbed back into OLA forming new precursor. The latter acts as ligand and solvent. Therefore, making OLAHS releases energy with high atom economy and using it yields a cleaner product whose excess reagents can be easily recycled (Fig. 1b).

Characterization and versatility of OLAHS. OLAHS can be produced by bubbling $\mathrm{H}_{2} \mathrm{~S}$ (either from a cylinder or produced in situ, e.g., by a reaction between bulk metal sulfide ores with an acid) into OLA. The reaction is exothermic $\left(\Delta H_{298}{ }^{0}=-93.05 \mathrm{~kJ} \mathrm{~mol}^{-1}\right.$ for $\mathrm{NH}_{3}+\mathrm{H}_{2} \mathrm{~S}=\mathrm{NH}_{4} \mathrm{HS}^{46}$ ) and forms a stable, highly viscous fluid (it flows readily above $35-40^{\circ} \mathrm{C}$; mesitylene or other organic solvents can also be added to decrease its viscosity and facilitate handling at room temperature).

Charge separation causes the appearance of a broad and weak FTIR absorption shoulder at $\sim 2520 \mathrm{~cm}^{-1}$ (Fig. 2a), which is attributed to the ion $\mathrm{NH}^{3+} \ldots \mathrm{SH}^{-47}$, and of a weak peak at 2564 $\mathrm{cm}^{-1}$ attributed to $\mathrm{S}-\mathrm{H}$ stretching vibration ${ }^{48,49}$. The symmetric and asymmetric stretching vibration from the amine $\left(v_{\mathrm{s}}\left(\mathrm{NH}_{2}\right)\right.$ and $v_{\text {as }}\left(\mathrm{NH}_{2}\right)$ at 3291 and $\left.3374 \mathrm{~cm}^{-1}\right)$ instead disappear ${ }^{47,50}$. A $10 \mathrm{~min}$ exposure to $120^{\circ} \mathrm{C}$ or $10^{-3}$ torr results in the recovery of the original amine vibration modes, indicating the dissociation of the ionic liquid into $\mathrm{H}_{2} \mathrm{~S}$ and OLA.

b

This work

Inputs

Products

Byproducts

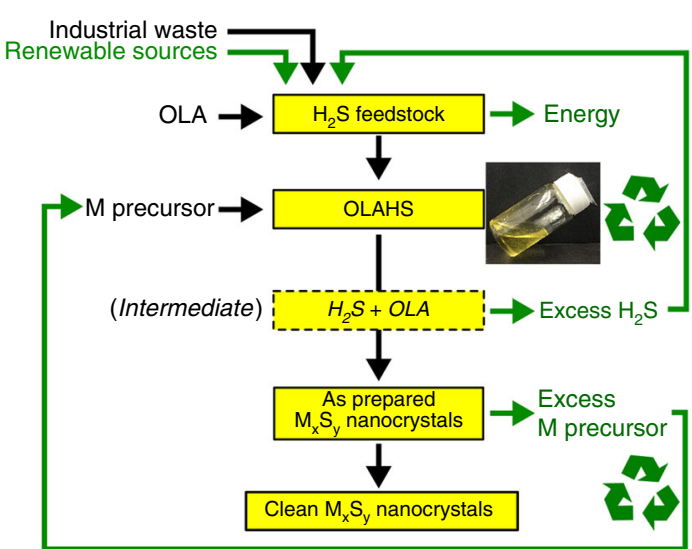

Fig. 1 Comparison of the inputs and by-products involved in metal sulfide nanoparticles syntheses. Using traditional precursors (a), and using the ionic liquid precursor described in this work (b). The inset shows a photograph of OLAHS at $35^{\circ} \mathrm{C}$. ' $M$ ' and ' $\mathrm{S}^{\prime}$ is short for 'metal' and 'sulfur', respectively. $\mathrm{M}_{x} \mathrm{~S}_{y}$ denotes a metal sulfide compound with an $\mathrm{M} / \mathrm{S}$ mole ratio of $x / y$ 
a - OLA - MSTL - $\mathrm{H}_{2}$ S bubbled MSTL - OLAHS in MSTL - OLAHS in MSTL (3 day) - OLAHS in MSTL $\left(120^{\circ} \mathrm{C} 10 \mathrm{~min}\right)$ - OLAHS in MSTL (RT vac $10 \mathrm{~min}$ )
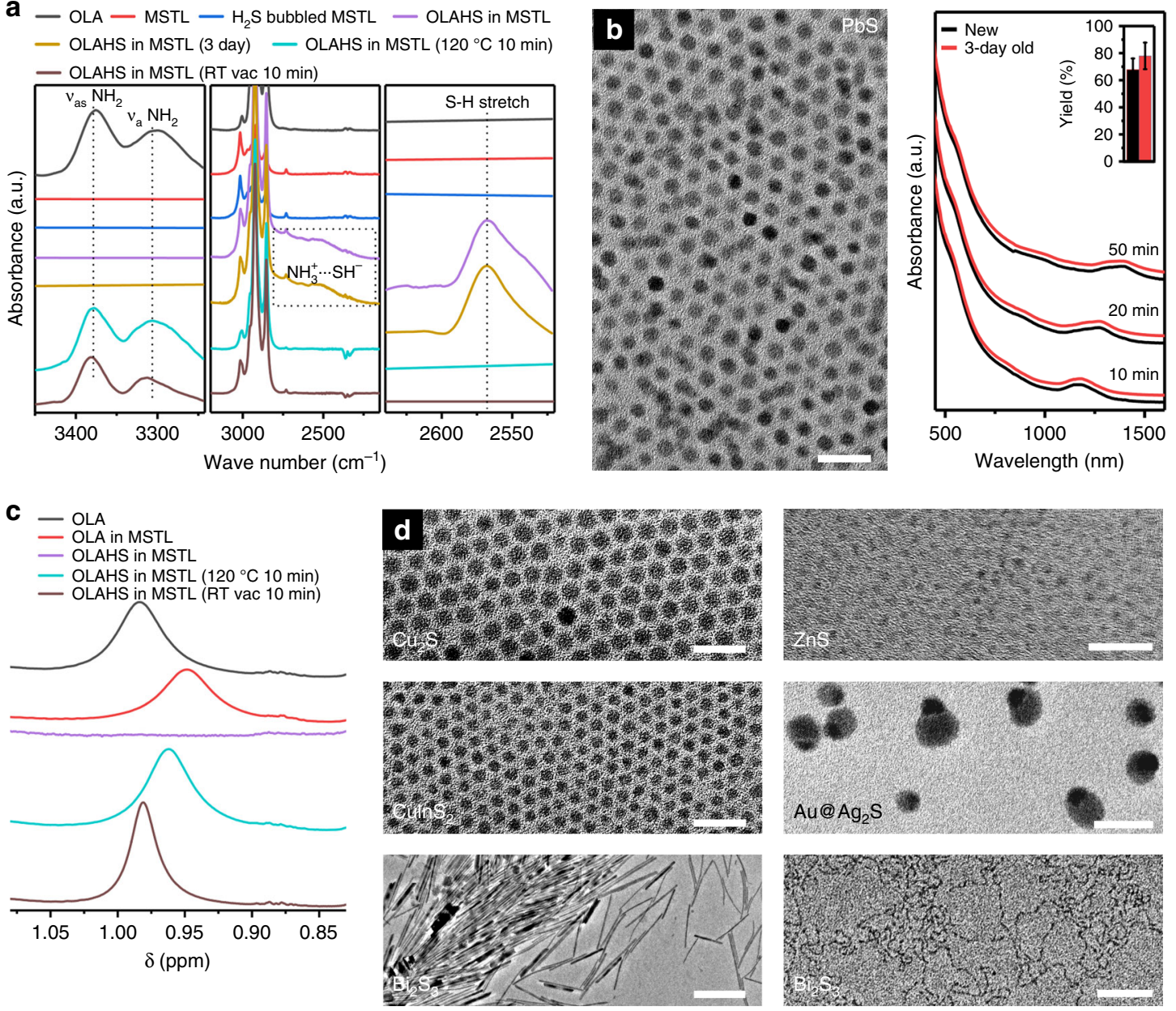

Fig. 2 Characterization of the OLAHS ionic liquid precursor and its application in the synthesis of chalcogenides nanocrystals. a Background-subtracted attenuated total reflectance Fourier-transform infrared (ATR-FTIR) absorption spectrum of oleylamine (black), mesitylene (red), mesitylene after being bubbled with $\mathrm{H}_{2} \mathrm{~S}$ (blue), OLAHS in mesitylene (purple), OLAHS in mesitylene (3-day old) (yellow), OLAHS in mesitylene after being kept at $120{ }^{\circ} \mathrm{C}$ for $10 \mathrm{~min}$ (green), and OLAHS in mesitylene after being kept under vacuum (10-3 Torr) at room temperature for 10 min (brown). 'MSTL', 'RT', and 'vac' is short for 'mesitylene', 'room temperature', and 'vacuum', respectively. b TEM image of the as-synthesized PbS nanocrystals using OLAHS (left) (scale bar: $20 \mathrm{~nm}$ ) and the UV-Vis-NIR absorption spectra for samples collected at different growth times (right) using a fresh (black) and 3-day old (red) OLAHS precursor. Inset: comparison of sulfur yield of reaction using fresh or 3-day old OLAHS as precursor. The error bars depict the standard deviation from

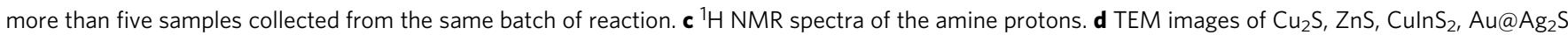
(janus nanoparticles), and $\mathrm{Bi}_{2} \mathrm{~S}_{3}$ nanocrystals synthesized using OLAHS as precursor (scale bar is $20 \mathrm{~nm}$ except for $\mathrm{Bi}_{2} \mathrm{~S}_{3}$ nanorods (scale bar: $180 \mathrm{~nm}$ ) and $\mathrm{Bi}_{2} \mathrm{~S}_{3}$ nanowires (scale bar: $40 \mathrm{~nm}$ )). All the spectra have been offset for clarity

The precursor is stable and yields highly reproducible nanoparticle syntheses. Three days of storage in a closed vial at room temperature did not change the FTIR spectrum of the precursor (Fig. 2a). Reactions that used fresh and 3-day-old OLAHS produced $\mathrm{PbS}$ quantum dots with closely matching optical spectra (Fig. 2b) throughout the course of the reaction. The difference in particle size between the two reactions was less than $0.04 \mathrm{~nm}$ based on the absorption spectra while the sulfur yield differed by $10.1 \%$ (mean). The sulfur yield (about $72.9 \%$ ) is comparable to or higher than the ones reported for other sulfur precursors, e.g., (TMS) ${ }_{2} \mathrm{~S}$ and sulfur ${ }^{51,52}$. The high stability and reproducibility (also see Supplementary Figure 7) are of great advantages over the most commonly used sulfur precursor $\mathrm{S}_{8} /$ OLA $^{53}$.

The FTIR results are supported by ${ }^{1} \mathrm{H}$ NMR data (Fig. $2 \mathrm{c}$ ). Upon charge separation, the proton peak from amine $(\sim 0.97$ $\mathrm{ppm}$ ) shifted downfield and broadened out (cf. Supplementary Figure 1). Upon exposure to heat or vacuum, the signal from the amine protons is recovered. The rapid release of $\mathrm{H}_{2} \mathrm{~S}$ by vacuum allows for the rapid termination of a synthesis, providing control over the growth of the nanoparticles even at room temperature (a major challenge with reactive, non-volatile sulfur precursors like (TMS $)_{2} S$ ) and greatly improving the safety of the reaction mixture (traditional precursors, such as the commonly used $\mathrm{S}_{8} / \mathrm{OLA}$ and $(\mathrm{TMS})_{2} \mathrm{~S}$, if in excess, release $\mathrm{H}_{2} \mathrm{~S}$ during the purification steps).

OLAHS acts as an effective general sulfur precursor for the synthesis of colloidal sulfide nanoparticles of various compositions ( $\mathrm{PbS}, \mathrm{Cu}_{2} \mathrm{~S}, \mathrm{ZnS}, \mathrm{Au} @ \mathrm{Ag}_{2} \mathrm{~S}, \mathrm{CuInS}_{2}, \mathrm{Bi}_{2} \mathrm{~S}_{3}$ ), sizes (from 3 to $7 \mathrm{~nm}$ ), and shapes (from spheres to rods to wires to janus particles) (Fig. 2d) (cf. Supplementary Figures 2-5 for the x-ray diffraction (XRD) patterns).

Using OLAHS allows for the recycling of excess precursors. At high temperatures, the ionic liquid dissociates completely during reaction and the unreacted $\mathrm{H}_{2} \mathrm{~S}$ is released as a gas. FTIR spectra show that crude reaction product $\left(10 \mathrm{~min}\right.$ at $\left.120^{\circ} \mathrm{C}\right)$ does not 

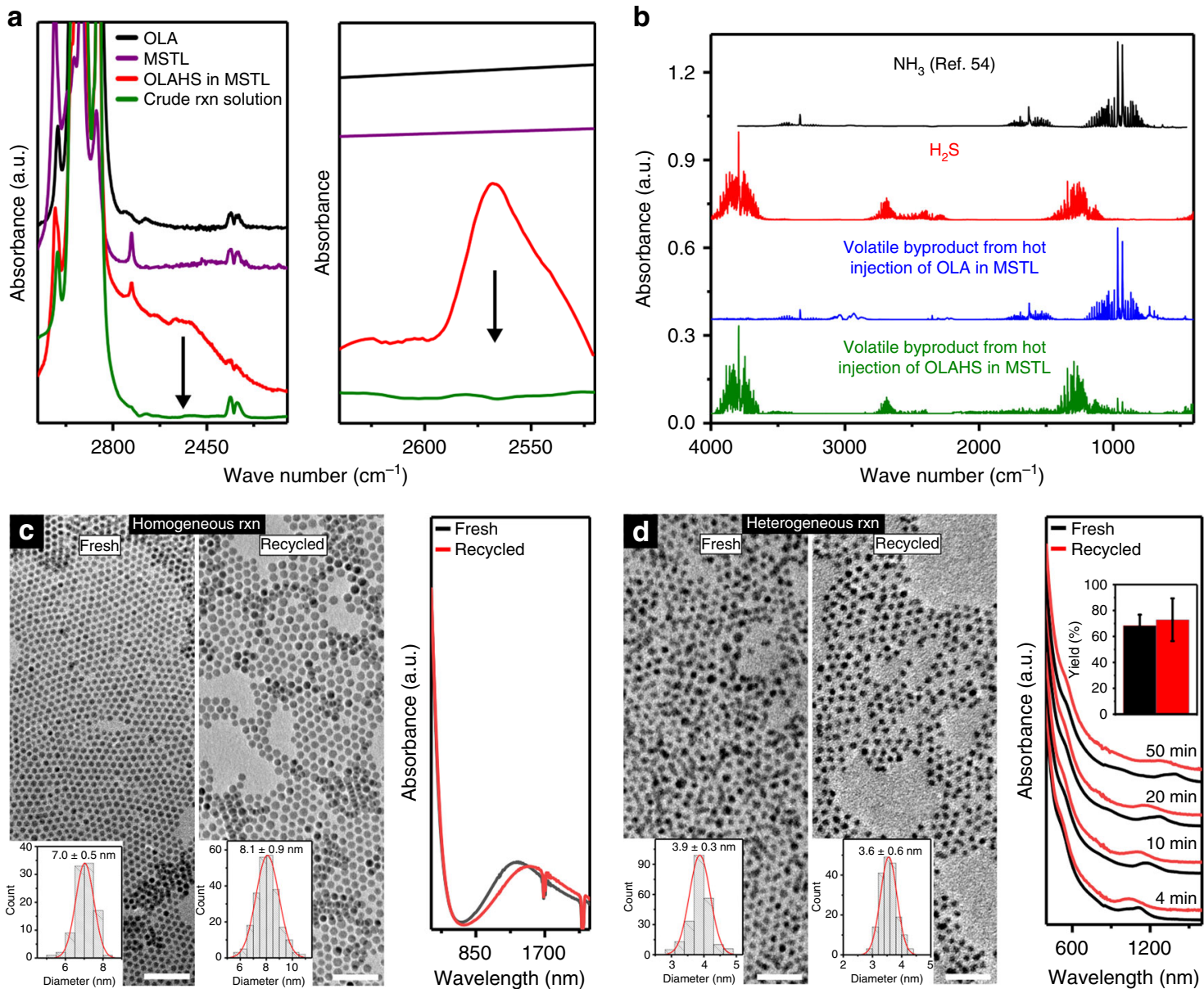

Fig. 3 Recyclability of unreacted $\mathrm{H}_{2} \mathrm{~S}$ and excess metal precursor from a homo/heterogeneous reaction using OLAHS. a Background-subtracted ATR-FTIR absorption spectra of a reaction mixture after synthesis of nanocrystals (green), compared to fresh OLAHS precursor (red) and controls (black and purple) indicating the absence of sulfur residual. $\mathbf{b}$ Gas-phase FTIR absorption spectra of the volatile reaction by-products (green) compared to volatile by-products of OLA (blue), shows that OLAHS releases $\mathrm{H}_{2} \mathrm{~S}$ (red) and $\mathrm{NH}_{3}$ (black). The $\mathrm{NH}_{3}$ spectrum is from ref. ${ }^{54}$. c TEM images (left) (scale bar: $50 \mathrm{~nm}$ ) and UV-Vis-NIR absorption spectra (right) of the as-synthesized $\mathrm{Cu}_{2} \mathrm{~S}$ nanoparticles using fresh (balck) and recycled (red) copper precursor. Inset: size distribution of the nanocrystals. d TEM images (left) (scale bar: $25 \mathrm{~nm}$ ) and UV-Vis-NIR absorption spectra (right) of the as-synthesized PbS nanoparticles using fresh (black) and recycled (red) lead precursor. Insets: Size distribution of the nanocrystals and sulfur yield. The error bars depict the standard deviation from more than five samples collected from the same batch of reaction. All the spectra have been offset for clarity

show absorption from $\mathrm{NH}^{3+} \ldots \mathrm{SH}^{-}$bonds or from S-H bonds (Fig. 3a). FTIR analysis of the volatile by-products (Fig. 3b) identified them as a mixture of $\mathrm{H}_{2} \mathrm{~S}$ and $\mathrm{NH}_{3}$ (present in OLA).

The lack of sulfur by-products is a very significant sustainability advantage over other precursors, like $\mathrm{S}_{8} / \mathrm{OLA}$, which produce complex mixtures of chemicals ${ }^{27}$. OLAHS lead to the formation of a minimal number of by-products, specifically (at least for ionic metal precursors, like oleates, acetates, chlorides) the conjugate acid of the metal precursor's anion. Depending on the choice of metal precursor, this by-product can be also removed easily from the reaction mixture (e.g., $\mathrm{HCl}$ from $\mathrm{PbCl}_{2}$ ). The spontaneous separation of the excess sulfur from the reaction mixture and the minimal amounts of by-products allows for ligands, excess metal precursors, and solvents to be easily recycled and reused. Recycling, if not too resource intensive, is essential for sustainability as it increases atom economy and reduces waste. This is especially true for reactions, like most nanocrystal syntheses, that are conducted with large excesses of one reagent ${ }^{13}$ and that are terminated before completion ${ }^{15}$. In the case of homogeneous reactions, i.e., where the metal precursor is fully solubilized, the mixture of unreacted precursor and ligands can be replenished with fresh precursor and reused in the following reaction. For example, Fig. $3 c$ compares $\mathrm{Cu}_{2} \mathrm{~S}$ nanocrystals obtained from fresh and recycled mixtures of $\mathrm{CuCl}$, OLAHS, and OLA. The products have identical particle shape, and comparable particle size and UV-Vis-NIR absorption spectrum.

In the case of heterogeneous reactions, i.e., where the majority of the metal precursor is present as a solid ${ }^{23}$, recycling of the unreacted metal precursor is even simpler: excess precursor is recovered by centrifugation and reused. $\mathrm{PbS}$ nanocrystals with low polydispersity $(3.9 \pm 0.3 \mathrm{~nm})$ were synthesized in high sulfur yields $(\sim 68 \%)$ by reacting a slurry of $\mathrm{PbCl}_{2}$ in OLA with OLAHS (Fig. 3d). Recycled $\mathrm{PbCl}_{2}$ was used in a follow-up reaction leading to monodisperse colloids of similar size and polydispersity $(3.6 \pm$ $0.6 \mathrm{~nm})$ in similar sulfur yields $(\sim 73 \%)$.

Synthesis of metal sulfides nanocrystals under ambient condition and large scale/high concentration. Besides minimizing waste generation, carrying out syntheses under ambient condition (in air, at room temperature) on a large scale, while minimizing auxiliaries (here, minimizing the use of solvents) are essential features of green chemistry processes. In nanocrystal synthesis, these requirements appear to be mutually exclusive: increasing the concentration of the product, usually requires high temperatures, and reaction times (e.g., $180^{\circ} \mathrm{C}$ for a few hours) $)^{13}$. To 

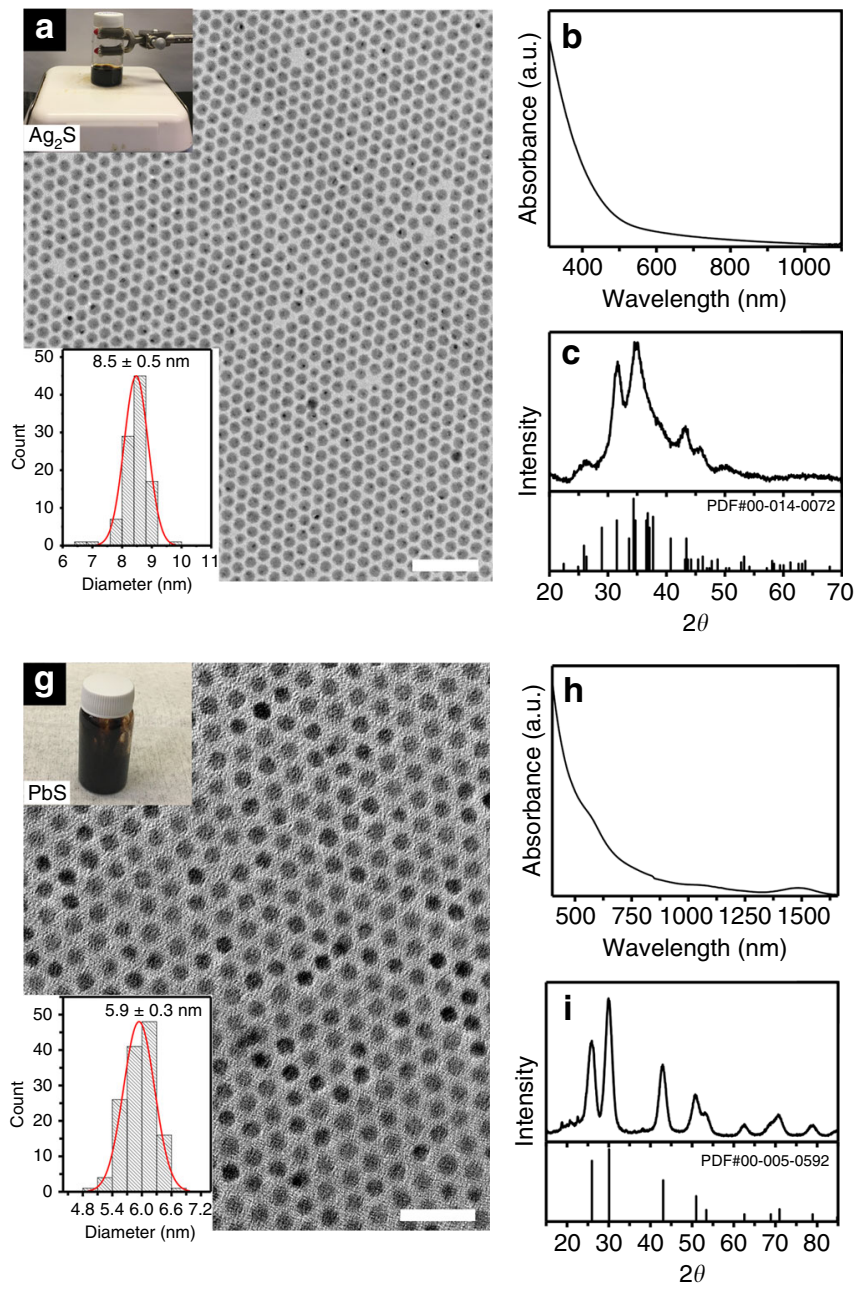
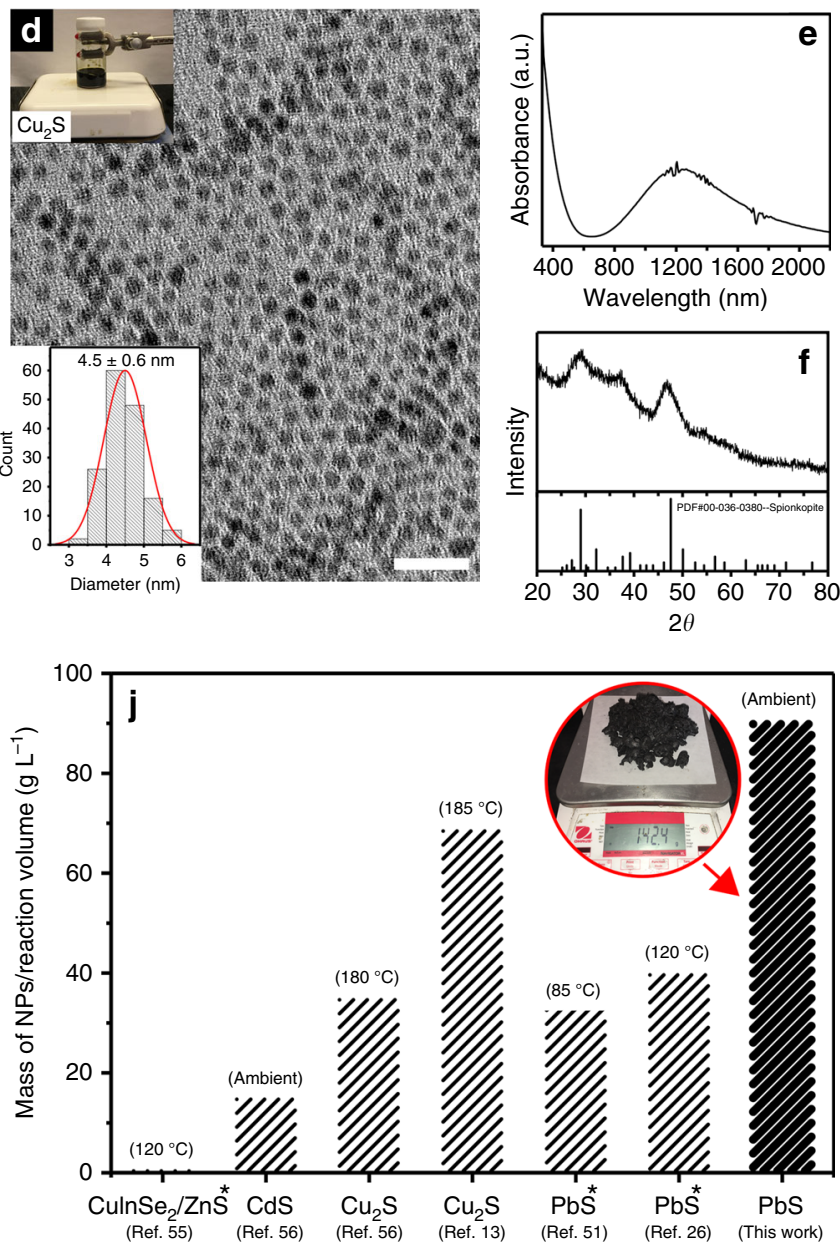

Fig. 4 Reaction in ambient conditions and concentration intensification using OLAHS. a-c TEM image (scale bar: 50 nm) with photograph of reaction condition and nanocrystal size distribution, UV-Vis-NIR absorption spectrum, and XRD pattern of $\mathrm{Ag}_{2} \mathrm{~S}$ nanocrystals synthesized under ambient conditions. d-f TEM image (scale bar: $20 \mathrm{~nm}$ ) with photograph of reaction condition and nanocrystal size distribution, UV-Vis-NIR absorption spectrum, and XRD pattern of $\mathrm{Cu}_{2} \mathrm{~S}$ nanocrystals synthesized under ambient conditions. $\mathbf{g}$-i TEM image (scale bar: 25 nm) with photograph of reaction condition and nanocrystal size distribution, UV-Vis-NIR absorption spectrum, and XRD pattern of PbS nanocrystals synthesized under ambient conditions. $\mathbf{j}$ Comparison of $\mathrm{PbS}$ nanocrystal concentration $\left(\mathrm{g} \mathrm{L}^{-1}\right)$ in our crude reaction product with reported large-scale syntheses ${ }^{13,26,51,55,56}$. ${ }^{\star}$ Indicates concentrations that include the capping ligand. Inset: photograph of $142.4 \mathrm{~g}$ of PbS nanocrystals synthesized in a single $1.18 \mathrm{~L}$ batch in ambient conditions

this day, even though some of the sulfur precursors are, in principle, reactive enough for room temperature synthesis ${ }^{56-59}$, they are too expensive ((TMS) $\left.)_{2} \mathrm{~S}\right)$, require time-consuming energy-intensive steps to use $\left((\mathrm{NH} 4)_{2} \mathrm{~S}^{56}\right)$, or require inert atmospheres ((TMS) $\left.{ }_{2} \mathrm{~S}^{57}\right)$.

Several technologically relevant sulfides could be synthesized with OLAHS in ambient conditions as high-quality nanocrystals. Monodisperse $\mathrm{Ag}_{2} \mathrm{~S}$ nanoparticles with a diameter of $8.5 \pm 0.5 \mathrm{~nm}$ were synthesized using OLAHS in ambient conditions using silver nitrate as a metal precursor (Fig. 4a). The lack of a distinct excitonic absorption peak in the UV-Vis absorption spectrum (Fig. 4b) is consistent with previous reports ${ }^{60,61}$, while the XRD pattern (Fig. 4c) is consistent with the acanthite phase of $\mathrm{Ag}_{2} \mathrm{~S}$. $\mathrm{Cu}_{2} \mathrm{~S}$ was also synthesized in ambient conditions with OLAHS (Fig. $4 \mathrm{~d}-\mathrm{f}$ ) using $\mathrm{Cu}(\mathrm{I})$ acetate as a metal precursor. Since $\mathrm{Cu}_{2} \mathrm{~S}$ is an indirect bandgap semiconductor, the UV-Vis absorption spectrum (Fig. 4e) is featureless below $\sim 600 \mathrm{~nm}$, while the absorption above $600 \mathrm{~nm}$ is due to a localized surface plasmon resonance ${ }^{62}$. While Scherrer broadening prevents a conclusive phase determination, the XRD pattern (Fig. 4f) best matches with one of spionkopite phases. ${ }^{63}$ Synthesis in ambient conditions can be further simplified by combining the synthesis of OLAHS with the synthesis of the nanocrystals in one pot, i.e. combining $\mathrm{H}_{2} \mathrm{~S}$ with OLA in the presence of the metal precursor. Highly monodisperse $\mathrm{PbS}$ nanocrystals (diameter $5.9 \pm 0.3 \mathrm{~nm}$ ) were produced (Fig. $4 \mathrm{~g}$ ). This high monodispersity is attributed to the high concentrations $(0.864 \mathrm{M}$ of metal precursor) used for the synthesis $^{13}$. The UV-Vis-NIR absorption spectrum and XRD pattern of the as-prepared PbS nanocrystals are shown in Fig. 4h, $\mathrm{i}$, respectively. Scaling this approach to a $1.18 \mathrm{~L}$ reaction volume yielded $142.4 \mathrm{~g}$ of purified $\mathrm{PbS}$ nanoparticles (cf. Supplementary Figure 8 for the TEM images). Excluding the weight of the ligand ( $25 \mathrm{wt} \%$, as determined by NMR) the net concentration of the product was $90.2 \mathrm{~g} \mathrm{~L}^{-1}$. This concentration compares favorably to the reported concentrations of metal chalcogenide nanoparticles in crude reaction product from large-scale synthesis (180\% higher than the concentration ${ }^{51}$ from a reaction using (TMS $)_{2} \mathrm{~S}$ at $85^{\circ} \mathrm{C}$, and $31 \%$ higher than the highest net concentration ever reported $\left(68.8 \mathrm{~g} \mathrm{~L}^{-1}\right)^{13}$ (Fig. 4j).

Synthesis of metal sulfides nanocrystals at relatively low cost. The commercial viability of colloidal metal sulfide nanocrystals is 
intimately connected to their synthesis $\operatorname{cost}^{64}$. Low synthesis cost can be mainly achieved ${ }^{64}$ by (i) high-energy efficiency of the synthetic procedure, (ii) low chemical/reagent cost, and (iii) low labor cost. As shown above, this ionic liquid OLAHS sulfur precursor provides high-energy efficiency because energy intensive steps in making the sulfur precursor from $\mathrm{H}_{2} \mathrm{~S}$ are avoided (Fig. 1) and high temperatures and inert reaction conditions are replaced with ambient condition (i.e. at room temperature in air). Chemical/reagent cost, in principle, can be very low because this sulfur precursor can be made in one step from the main feedstock and reaction solvent can be very efficiently used via recycling and high precursor concentration ${ }^{64}$. Lastly, high reproducibility (i.e. robustness) of the synthetic procedure and large reaction scale, as shown above, allow for the lowering of labor costs ${ }^{64}$.

In summary, we have demonstrated a simple solution to a complex and long-standing problem in nanocrystal synthesis, specifically the sustainable synthesis of high-quality colloidal nanocrystals of chalcogenide phases. This approach fulfills all the most significant principles of green chemistry, including high atom economy and waste prevention through high reaction yields and recycling, energy efficiency and minimization of derivatives through the elimination of energy-intensive reaction steps, use of renewable feedstocks by using $\mathrm{H}_{2} \mathrm{~S}$ and OLA (both renewable), minimization of auxiliaries through high precursor concentrations and reduction of by-products, and accident prevention by the facile and safe removal of $\mathrm{H}_{2} \mathrm{~S}$ excess from the reaction mixture. The work shows the potential of ionic liquids for the stabilization of highly reactive, volatile precursors for sustainable nanoparticle synthesis that can reach high yields, at high concentrations and ambient temperatures, while reducing byproducts and enabling recycling. It also shows the potential of ionic liquids for lowering the cost of colloidal nanocrystals and in turn increasing their commercial viability.

\section{Data availability}

The data is available in the article, the Supplementary Information, and from the corresponding author upon request.

Received: 12 June 2018 Accepted: 10 September 2018

Published online: 04 October 2018

\section{References}

1. Dahl, J. A., Maddux, B. L. \& Hutchison, J. E. Toward greener nanosynthesis. Chem. Rev. 107, 2228-2269 (2007)

2. Reiss, P., Carriere, M., Lincheneau, C., Vaure, L. \& Tamang, S. Synthesis of semiconductor nanocrystals, focusing on nontoxic and earth-abundant materials. Chem. Rev. 116, 10731-10819 (2016).

3. Mao, Y., Park, T. J., Zhang, F., Zhou, H. \& Wong, S. S. Environmentally friendly methodologies of nanostructure synthesis. Small 3, 1122-1139 (2007).

4. Anastas, P. \& Eghbali, N. Green chemistry: principles and practice. Chem. Soc. Rev. 39, 301-312 (2010).

5. Murphy, C. J. Sustainability as an emerging design criterion in nanoparticle synthesis and applications. J. Mater. Chem. 18, 2173-2176 (2008).

6. Virkutyte, J. \& Varma, R. S. Green synthesis of metal nanoparticles: biodegradable polymers and enzymes in stabilization and surface functionalization. Chem. Sci. 2, 837-846 (2011).

7. Torres Galvis, H. M. et al. Supported iron nanoparticles as catalysts for sustainable production of lower olefins. Science 335, 835-838 (2012).

8. Kharissova, O. V., Dias, H. V. R., Kharisov, B. I., Pérez, B. O. \& Pérez, V. M. J. The greener synthesis of nanoparticles. Trends Biotechnol. 31, 240-248 (2013).

9. Gilbertson, L. M., Zimmerman, J. B., Plata, D. L., Hutchison, J. E. \& Anastas, P. T. Designing nanomaterials to maximize performance and minimize undesirable implications guided by the principles of green chemistry. Chem. Soc. Rev. 44, 5758-5777 (2015).

10. Park, J. et al. Ultra-large-scale syntheses of monodisperse nanocrystals. Nat. Mater. 3, 891 (2004).
11. Behrens, S. H., Breedveld, V., Mujica, M. \& Filler, M. A. Process principles for large-scale nanomanufacturing. Annu. Rev. Chem. Biomol. Eng. 8, 201-226 (2017).

12. de Mello Donegá, C., Liljeroth, P. \& Vanmaekelbergh, D. Physicochemical evaluation of the hot-injection method, a synthesis route for monodisperse nanocrystals. Small 1, 1152-1162 (2005).

13. Williamson, C. B., Nevers, D. R., Hanrath, T. \& Robinson, R. D. Prodigious effects of concentration intensification on nanoparticle synthesis: a highquality, scalable approach. J. Am. Chem. Soc. 137, 15843-15851 (2015).

14. Chemseddine, A. \& Weller, H. Highly monodisperse quantum sized CdS particles by size selective precipitation. Ber. Bunsen-Ges. Phys. Chem. 97, 636-638 (1993).

15. Peng, X. G., Wickham, J. \& Alivisatos, A. P. Kinetics of II-VI and III-V colloidal semiconductor nanocrystal growth: "Focusing" of size distributions. J. Am. Chem. Soc. 120, 5343-5344 (1998).

16. Iravani, S. Green synthesis of metal nanoparticles using plants. Green Chem. 13, 2638-2650 (2011).

17. Raveendran, P., Fu, J. \& Wallen, S. L. Completely "green" synthesis and stabilization of metal nanoparticles. J. Am. Chem. Soc. 125, 13940-13941 (2003).

18. Sangeetha, G., Rajeshwari, S. \& Venckatesh, R. Green synthesis of zinc oxide nanoparticles by aloe barbadensis miller leaf extract: structure and optical properties. Mater. Res. Bull. 46, 2560-2566 (2011).

19. Baruwati, B., Polshettiwar, V. \& Varma, R. S. Glutathione promoted expeditious green synthesis of silver nanoparticles in water using microwaves. Green Chem. 11, 926-930 (2009).

20. Hebbalalu, D., Lalley, J., Nadagouda, M. N. \& Varma, R. S. Greener techniques for the synthesis of silver nanoparticles using plant extracts, enzymes, bacteria, biodegradable polymers, and microwaves. ACS Sustain. Chem. Eng. 1, 703-712 (2013).

21. Raveendran, P., Fu, J. \& Wallen, S. L. A simple and "green" method for the synthesis of $\mathrm{Au}, \mathrm{Ag}$, and $\mathrm{Au}-\mathrm{Ag}$ alloy nanoparticles. Green Chem. 8, 34-38 (2006).

22. Yuan, B., Brandt, J. A., Shaw, S., Mohapatra, P. \& Cademartiri, L. Towards bulk syntheses of nanomaterials: a homeostatically supersaturated synthesis of polymer-like $\mathrm{Bi}_{2} \mathrm{~S}_{3}$ nanowires with $100 \%$ yield and no injection. RSC Adv. 6, 113815-113819 (2016).

23. Cademartiri, L. \& Ozin, G. A. Emerging strategies for the synthesis of highly monodisperse colloidal nanostructures. Philos. Trans. R. Soc. A 368, $4229-4248$ (2010).

24. Ma, X., Wang, X. \& Song, C. "Molecular basket" sorbents for separation of $\mathrm{CO}_{2}$ and $\mathrm{H}_{2} \mathrm{~S}$ from various gas streams. J. Am. Chem. Soc. 131, 5777-5783 (2009).

25. Kohl, A. L. \& Nielsen, R. Gas Purification (Elsevier, Houston, Texas 1997).

26. Hendricks, M. P., Campos, M. P., Cleveland, G. T., Jen-La Plante, I. \& Owen, J. S. A tunable library of substituted thiourea precursors to metal sulfide nanocrystals. Science 348, 1226-1230 (2015).

27. Thomson, J. W., Nagashima, K., Macdonald, P. M. \& Ozin, G. A. From sulfuramine solutions to metal sulfide nanocrystals: peering into the oleylaminesulfur black box. J. Am. Chem. Soc. 133, 5036-5041 (2011).

28. van Embden, J., Chesman, A. S. \& Jasieniak, J. J. The heat-up synthesis of colloidal nanocrystals. Chem. Mater. 27, 2246-2285 (2015).

29. Jung, Y. K., Kim, J. I. \& Lee, J.-K. Thermal decomposition mechanism of single-molecule precursors forming metal sulfide nanoparticles. J. Am. Chem. Soc. 132, 178-184 (2009).

30. Wang, S., Gao, Q. \& Wang, J. Thermodynamic analysis of decomposition of thiourea and thiourea oxides. J. Phys. Chem. B 109, 17281-17289 (2005).

31. Cao, Y. et al. Thiolate-mediated photoinduced synthesis of ultrafine $\mathrm{Ag}_{2} \mathrm{~S}$ quantum dots from silver nanoparticles. Angew. Chem. Int. Ed. 55, 14952-14957 (2016).

32. Broderick, E. M., Serban, M., Mezza, B. \& Bhattacharyya, A. Scientific approach for a cleaner environment using ionic liquids. ACS Sustain. Chem. Eng. 5, 3681-3684 (2017).

33. Plechkova, N. V. \& Seddon, K. R. Applications of ionic liquids in the chemical industry. Chem. Soc. Rev. 37, 123-150 (2008).

34. da Costa Lopes, A. M. \& Bogel-Łukasik, R. Acidic ionic liquids as sustainable approach of cellulose and lignocellulosic biomass conversion without additional catalysts. ChemSusChem 8, 947-965 (2015).

35. Hallett, J. P. \& Welton, T. Room-temperature ionic liquids: solvents for synthesis and catalysis. 2. Chem. Rev. 111, 3508-3576 (2011).

36. Zhang, Q., Zhang, S. \& Deng, Y. Recent advances in ionic liquid catalysis. Green Chem. 13, 2619-2637 (2011).

37. Sheldon, R. A. Green solvents for sustainable organic synthesis: state of the art. Green Chem. 7, 267-278 (2005).

38. Jiang, Y. \& Zhu, Y.-J. Microwave-assisted synthesis of sulfide $\mathrm{M}_{2} \mathrm{~S}_{3}(\mathrm{M}=\mathrm{Bi}, \mathrm{Sb})$ nanorods using an ionic liquid. J. Phys. Chem. B 109, 4361-4364 (2005).

39. Ma, Z., Yu, J. \& Dai, S. Preparation of inorganic materials using ionic liquids. Adv. Mater. 22, 261-285 (2010). 
40. Zhou, Y. \& Antonietti, M. Synthesis of very small $\mathrm{TiO}_{2}$ nanocrystals in a room-temperature ionic liquid and their self-assembly toward mesoporous spherical aggregates. J. Am. Chem. Soc. 125, 14960-14961 (2003).

41. Antonietti, M., Kuang, D., Smarsly, B. \& Zhou, Y. Ionic liquids for the convenient synthesis of functional nanoparticles and other inorganic nanostructures. Angew. Chem. Int. Ed. 43, 4988-4992 (2004)

42. Taubert, A. CuCl nanoplatelets from an ionic liquid-crystal precursor. Angew. Chem. Int. Ed. 43, 5380-5382 (2004).

43. Wang, Y. \& Yang, H. Synthesis of CoPt nanorods in ionic liquids. J. Am. Chem. Soc. 127, 5316-5317 (2005).

44. Koech, P. K., Rainbolt, J. E., Bearden, M. D., Zheng, F. \& Heldebrant, D. J. Chemically selective gas sweetening without thermal-swing regeneration. Energy Environ. Sci. 4, 1385-1390 (2011).

45. Mourdikoudis, S. \& Liz-Marzán, L. M. Oleylamine in nanoparticle synthesis. Chem. Mater. 25, 1465-1476 (2013).

46. Hull, C. International Critical Tables of Numerical Data, Physics, Chemistry and Technology. Vol. 5 (National Academies, New York, New York 1929).

47. Miller, D. D. \& Chuang, S. S. The effect of electron-donating groups and hydrogen bonding on $\mathrm{H}_{2} \mathrm{~S}$ capture over polyethylene glycol/amine sites. J. Phys. Chem. C 120, 1147-1162 (2016).

48. Huang, H. Y., Yang, R. T., Chinn, D. \& Munson, C. L. Amine-grafted MCM48 and silica xerogel as superior sorbents for acidic gas removal from natural gas. Ind. Eng. Chem. Res. 42, 2427-2433 (2003).

49. Loeffler, M. J., Hudson, R. L., Chanover, N. J. \& Simon, A. A. Giant-planet chemistry: amonium hydrosulfide $\left(\mathrm{NH}_{4} \mathrm{SH}\right)$, its IR spectra and thermal and radiolytic stabilities. Icarus 258, 181-191 (2015).

50. Zhang, J., Srivastava, R. \& Misra, R. Core-shell magnetite nanoparticles surface encapsulated with smart stimuli-responsive polymer: synthesis, characterization, and LCST of viable drug-targeting delivery system. Langmuir 23, 6342-6351 (2007).

51. Zhang, J., Gao, J., Miller, E. M., Luther, J. M. \& Beard, M. C. Diffusioncontrolled synthesis of $\mathrm{PbS}$ and $\mathrm{PbSe}$ quantum dots with in situ halide passivation for quantum dot solar cells. ACS Nano 8, 614-622 (2014).

52. Li, Z., Ji, Y., Xie, R., Grisham, S. Y. \& Peng, X. Correlation of CdS nanocrystal formation with elemental sulfur activation and its implication in synthetic development. J. Am. Chem. Soc. 133, 17248-17256 (2011).

53. Lynch, Michael, An Investigation of Solutions of Sulfur in Oleylamine by Raman Spectroscopy and Their Relation to Lead Sulfide Quantum Dot Synthesis. Undergraduate Honors Theses. 1389 (2017). https://scholar colorado.edu/honr_theses/1389

54. Coblentz Society, Inc., "Evaluated infrared reference spectra" in NIST chemistry webbook. In NIST Standard Reference Database number 69 (eds Linstrom, P.J. \& Mallard, W. G.) (National Institute of Standards and Technology, Gaithersburg, MD, 2018).

55. Kang, X. et al. Large-scale synthesis of water-soluble CuInSe $2 / \mathrm{ZnS}$ and $\mathrm{AgInSe}_{2} / \mathrm{ZnS}$ core/shell quantum dots. Green Chem. 17, 4482-4488 (2015).

56. Zhang, H., Hyun, B.-R., Wise, F. W. \& Robinson, R. D. A generic method for rational scalable synthesis of monodisperse metal sulfide nanocrystals. Nano Lett. 12, 5856-5860 (2012).

57. Lu, H. \& Brutchey, R. L. Tunable room-temperature synthesis of coinage metal chalcogenide nanocrystals from N-heterocyclic carbene synthons. Chem. Mater. 29, 1396-1403 (2017).

58. Yang, J. \& Ying, J. Y. Room-temperature synthesis of nanocrystalline $\mathrm{Ag}_{2} \mathrm{~S}$ and its nanocomposites with gold. Chem. Commun. 22, 3187-3189 (2009).

59. Liu, M. et al. Room-temperature synthesis of covellite nanoplatelets with broadly tunable localized surface plasmon resonance. Chem. Mater. 27, 2584-2590 (2015).
60. Dong, B. et al. Facile synthesis of highly photoluminescent $\mathrm{Ag}_{2} \mathrm{Se}$ quantum dots as a new fluorescent probe in the second near-infrared window for in vivo imaging. Chem. Mater. 25, 2503-2509 (2013).

61. Xie, R., Rutherford, M. \& Peng, X. Formation of high-quality I-III-VI semiconductor nanocrystals by tuning relative reactivity of cationic precursors. J. Am. Chem. Soc. 131, 5691-5697 (2009).

62. Xie, Y. et al. Metallic-like stoichiometric copper sulfide nanocrystals: phaseand shape-selective synthesis, near-infrared surface plasmon resonance properties, and their modeling. ACS Nano 7, 7352-7369 (2013).

63. Saldanha, P. L. et al. Generalized one-pot synthesis of copper sulfide, selenidesulfide, and telluride-sulfide nanoparticles. Chem. Mater. 26, 1442-1449 (2014).

64. Jean, J. et al. Synthesis cost dictates the commercial viability of lead sulfide and perovskite quantum dot photovoltaics. Energy Environ. Sci. https://doi.org/ $10.1039 / \mathrm{c} 8 \mathrm{ee} 01348 \mathrm{a}(2018)$

\section{Acknowledgements}

The work described in this paper has been supported by the Member-Specific-ResearchIntel program of Semiconductor Research Corporation under Award no. 2015-IN-2582. Preliminary work was funded by Iowa State University through a startup grant to L.C. The authors are grateful to Matthew G. Panthani for access to UV-Vis-NIR instrumentation.

\section{Author contributions}

L.C. and B.Y. designed the experiment; B.Y. synthesized the nanocrystals and performed FTIR, UV-Vis-NIR, XRD, and TEM characterization; V.V. and T.K.E. performed and analyzed ${ }^{1} \mathrm{H}$ NMR measurements. B.Y. and L.C. analyzed the rest of the data and wrote the paper.

\section{Additional information}

Supplementary Information accompanies this paper at https://doi.org/10.1038/s41467018-06549-8.

Competing interests: The authors declare no competing interests.

Reprints and permission information is available online at http://npg.nature.com/ reprintsandpermissions/

Publisher's note: Springer Nature remains neutral with regard to jurisdictional claims in published maps and institutional affiliations.

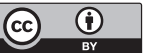

Open Access This article is licensed under a Creative Commons Attribution 4.0 International License, which permits use, sharing, adaptation, distribution and reproduction in any medium or format, as long as you give appropriate credit to the original author(s) and the source, provide a link to the Creative Commons license, and indicate if changes were made. The images or other third party material in this article are included in the article's Creative Commons license, unless indicated otherwise in a credit line to the material. If material is not included in the article's Creative Commons license and your intended use is not permitted by statutory regulation or exceeds the permitted use, you will need to obtain permission directly from the copyright holder. To view a copy of this license, visit http://creativecommons.org/ licenses/by/4.0/.

(c) The Author(s) 2018 